\title{
End-of-life home care utilization and costs in patients with advanced colorectal
}

\section{cancer}

\author{
Nicole Mittmann, PhD, ${ }^{1-4}$ Ning Liu, MSc, ${ }^{5}$ Joan M Porter, MSc, ${ }^{5}$ Pierre K Isogai, BSc, ${ }^{1}$ \\ Refik Saskin, MSc, ${ }^{5}$ Matthew C Cheung, MD, ${ }^{6}$ Natasha B Leighl, MD, MSc, ${ }^{7}$ Jeffrey S \\ Hoch, PhD $, 4,8,9$ Maureen E Trudeau, MD, MA, ${ }^{6}$ William K Evans, MD ${ }^{10}$ Katie N Dainty, \\ $\mathrm{PhD},{ }^{9}$ and Craig C Earle, $\mathrm{MD}, \mathrm{MSc}^{5,6}$
}

${ }^{1}$ Health Outcomes and PharmacoEconomic (HOPE) Research Centre, Sunnybrook Health Sciences Centre, Toronto, Ontario, Canada; ${ }^{2}$ Department of Pharmacology, University of Toronto, Ontario; ${ }^{3}$ International Centre for Health Innovation, Richard Ivey School of Business, University of Western Ontario, London; ${ }^{4}$ Canadian Centre for Applied Research in Cancer Control, Toronto; ${ }^{5}$ Institute for Clinical Evaluative Sciences, Toronto; ${ }^{6}$ Odette Cancer Centre, Sunnybrook Health Sciences Centre; ${ }^{7}$ Princess Margaret Hospital, Toronto; ${ }^{8}$ Pharmacoeconomics Research Unit, Cancer Care Ontario, ${ }^{9}$ Li Ka Shing Knowledge Institute, St. Michael's Hospital, Toronto; and ${ }^{10}$ Juravinski Cancer Centre, Hamilton, Ontario.

Objective To determine overall utilization and costs associated with home care services in Ontario, Canada by linking a home care database to a stage IV colorectal cancer cohort.

Methods The names of patients with stage IV colorectal cancer at time of diagnosis (diagnosed from 2005 through 2009 ) were extracted from the Ontario Cancer Registry. The study cohort comprised those who died before the end of the study. The terminal phase of care was the period of time between diagnosis and death, with a maximum value of 180 days (6 months). Patients were linked to home care services datasets. The type, frequency, and cost of home care services were determined. Regression analysis was used to examine factors associated with utilization and cost.

Results In all, 3,613 stage IV colorectal cancer patients (median age, 71 years) were diagnosed and died during the study's time horizon. During the terminal phase, $79.3 \%$ received at least 1 home care visit, and $58.0 \%$ had at least 1 palliative visit. Terminal metastatic colorectal cancer patients received an average of 8 home care visits at Canadian $\$ 800$ within a 30-day time horizon. Home care costs were highest in the month before death. Male sex, a history of moderate or high utilization of health care services, and hospitalization were associated with lower home care costs.

Limitations Administrative data do not reveal the purpose, efficiency, effectiveness/sufficiency, quality, or appropriateness of home care.

Conclusion Patients with advanced colorectal cancer who were approaching death required a moderate level of home care support, resulting in costs of about $\$ 5,000$ over the 6-month time horizon.

Funding This study was conducted with the support of the Ontario Institute for Cancer Research and Cancer Care Ontario through funding provided by the government of Ontario. Data were provided by Cancer Care Ontario and the Institute for Clinical Evaluative Sciences. The ICES also provided funding for the study from an annual grant by the Ontario Ministry of Health and Longterm Care.

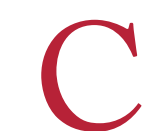
olorectal cancer is one of the leading causes of morbidity and mortality in Canada with 5 -year prevalence counts of $60,700 .{ }^{1}$ The number of new colorectal cancer patients diagnosed in the province of Ontario has increased by $117 \%$ over the past 3 decades. ${ }^{1}$ A recent report of community dwelling seniors showed that $25 \%$ received some sort of home care (formal and/or informal), and that the quantity of home care increased with age and disability. ${ }^{2}$ We hypothesized that home care services would be frequently used by patients with advanced colorectal cancer because of their need for medication administration and end-of life and/ or palliative support. Some studies have provided population-level costs for end-of-life care in terms of overall management across different diseases. ${ }^{3-6}$ Yet only a handful of population-based studies have examined home care utilization and the associated costs in persons with cancer. ${ }^{78}$ Most of the cancer studies used broadly defined cohorts and did not fo-

Accepted for publication September 24, 2013. Correspondence: Nicole Mittmann, PhD; nicole.mittmann@sri.utoronto.ca. Disclosures: The authors have no disclosures. JCSO 2014;12:92-98. (2014 Frontline Medical Communications. DOI 10.12788/jicso.0025. 
cus on a specific subtype of cancer. Few studies have examined home care in a colorectal-specific population. In 2007, researchers examined end-of-life medical expenditures in a US Medicare population in which patients had been diagnosed with colorectal cancer. ${ }^{9}$ In 2011, researchers examined end-of-life/palliative home care costs in adult oncology (incuding colorectal) patients in Ontario, based on administrative data. ${ }^{8}$

Ontario has a population of 13.2 million inhabitants, and some home care services for permanent residents are provided through its publicly funded health care system. The Ontario Ministry of Health and Long-term Care funds home care services (such as nursing care, personal support, and respite care) that are provided by and coordinated through community care access centres (CCACs). A record of the type and cost of each home care service delivered is captured in the Ontario Ministry of Health administrative database. This information is linkable to other administrative datasets including the Ontario Cancer Registry, which provides diagnostic and treatment data. ${ }^{10}$

The objective of this analysis was to link the Home Care Database the cohort with stage IV colorectal cancer to determine the overall utilization and costs associated with $\mathrm{CCAC}$-delivered home care services that were provided in the 6 months before death.

\section{Methods}

Incident patients with stage IV colorectal cancer (International Classification of Disease, ninth revision, ICD-9 153.x, ICD-9 154.x $)^{11}$ that was diagnosed from January 1, 2005, through December 31,2009, were extracted from the Ontario Cancer Registry. The Ontario Cancer Registry is a database of all Ontario residents who have been newly diagnosed with cancer, or who have died of cancer in Ontario. Cancer stage was based on the American Joint Committee on Cancer (AJCC) staging system, version $6 .{ }^{12} \mathrm{Re}-$ cords with missing stage information or an invalid health care number were excluded.

For this stage IV cohort, we focused on the terminal care phase, which was defined as the time between diagnosis and death, with a maximum value of 180 days. As a subanalysis, we also investigated patients who were alive for the entire 180-day period prior to death.

Colorectal cancer patients in the Ontario Cancer Registry were linked, by their encrypted health card number, to a number of administrative datasets for information on demographics, previous health care utilization, hospitalizations, and home care utilization. The administrative data were obtained from the Institute for Clinical Evaluative Sciences, and included the Ontario Home Care Administrative System (later replaced by the Home Care Database); the Registered Persons Database (demographics and death); and the Canadian Institute for Health Information (hospitalizations). The Institute for Clinical Evaluative
Sciences is an independent, not-for-profit organization; its core function is to conduct research that contributes to the effectiveness, quality, equity, and efficiency of health care and health services in Ontario.

Home care activities were defined as provincially funded visits from any of a variety of care providers, including nurses, physiotherapists, occupational therapists, respiratory services providers, nutritionists/dieticians, speech language pathologists, social workers, psychologists, patient management specialists, homemaking/personal support providers, placement services, and respite care providers. Each home care service provision was considered separately and was defined as a visit, and each visit was assumed to last 1 hour. The unit costs (in 2009 Canadian dollars on December 20, 2012, 1.00 Canadian dollar [1 Can\$] = 1.01 US dollar [1 US\$], at an exchange rate of 1.0118, using the nominal rate $)^{13}$ for home care services were obtained from the Ontario Ministry of Health and Long-term Care. ${ }^{14}$

Our main analysis included patients who died on or before March 31, 2010, subsequent to a diagnosis of colorectal cancer. The following analyses were conducted:

- Descriptive statistics,

- Mean weighted home care utilization and cost by the length of follow-up for each patient,

- Mean number of home care visits and costs over a 30day time frame, and

- Factors associated with home care cost per 30-day interval in the terminal care phase, based on multivariate linear regression analysis.

Only patients who received home care services were included in the regression analysis. The variables of interest were age, sex, income group, in-hospital death, and previous health care utilization. All analyses were performed with SAS 9.2 (SAS Institute Inc, Cary, North Carolina). For the subanalysis (namely, patients with a total of 180 days in the terminal care phase), home care visits and costs were examined at each month of the 6 months leading up to a patient's death.

\section{Results}

During the study's 2005-2009 time frame, 36,195 cases of new colorectal cancer were diagnosed in Ontario. Staging information was available for 25,224 (69.7\%) patients. Of the newly diagnosed patients, 5,282 were classified as stage IV at diagnosis. Demographic information is available in Table 1,15,16 and home care visits are described in Table 2. Over a 30-day period, patients with terminal metastatic colorectal cancer received, on average, 8 home care visits, or about 2 visits per week. The average cost of these visits was about Can $\$ 800$ per 30 days, or Can $\$ 200$ per week (Table 3 ). We assessed factors associated with 30-day cost (a dependent variable) using regression analysis among stage IV colorectal cancer patients who had utilized home care services. Male sex, moderate to high resource utilization in 


\begin{tabular}{|c|c|c|}
\hline Variable & Number & Percentage \\
\hline Patients with stage IV colorectal cancer & 3,613 & 100 \\
\hline Patients receiving home care during terminal phase & 2,866 & 79.3 \\
\hline \multicolumn{3}{|l|}{ Sex } \\
\hline Female & 1,635 & 45.3 \\
\hline Male & 1,978 & 54.7 \\
\hline \multicolumn{3}{|l|}{ Age, $y$} \\
\hline \multirow[t]{2}{*}{ Mean } & $(95 \% \mathrm{Cl})$ & 69.7 \\
\hline & (69.2-0.1) & NA \\
\hline \multirow[t]{2}{*}{ Median (IQR) } & 71 & \\
\hline & (61-79) & NA \\
\hline
\end{tabular}

$\begin{array}{lcr}\text { Age group, } y & & \\ <45 & 114 & 3.2 \\ 45-54 & 399 & 11.0 \\ 55-64 & 748 & 20.7 \\ 65-74 & 945 & 26.2 \\ 75-84 & 1,021 & 28.3 \\ \geq 85 & 386 & 10.7\end{array}$

$\begin{array}{lc}\text { Living in urban location } & \\ \text { Yes } 3,027 & 83.8 \\ \text { No } 584 & 16.2 \\ \text { Missing data } & 20.1\end{array}$

$\begin{array}{lcc}\begin{array}{l}\text { Modified income quintile } \\ \text { Urban residents }\end{array} & 613 & 17.0 \\ \text { Lowest } & & \\ \text { Second lowest } & 596 & 16.5 \\ \text { Middle } & 651 & 18.0 \\ \text { Second highest } & 575 & 15.9 \\ \text { Highest } & 589 & 16.3 \\ \text { Rural residents } & 581 & 16.1 \\ \text { Missing } & 8 & 0.2\end{array}$

$\begin{array}{lcc}\text { Resource Utilization Band } & & \\ \text { Healthy user } & 31 & 0.9 \\ \text { Low } & 168 & 4.6 \\ \text { Moderate } & 1,734 & 48.0 \\ \text { High } & 920 & 25.5 \\ \text { Highest } & 697 & 19.3 \\ \text { None } & 63 & 1.7\end{array}$

Had at least 1 palliative care code in

home care during terminal phase

$\begin{array}{lll}\text { No } & 1,516 & 42.0 \\ \text { Yes } & 2,097 & 58.0\end{array}$

$\begin{array}{lcc}\begin{array}{l}\text { Time between diagnosis and death, days } \\ \text { Mean }(95 \% \mathrm{CI})\end{array} & 311.2 & \\ & (300.9-321.4) & \mathrm{NA} \\ \text { Median (IQR) } & 198 & \\ & (69-463) & \mathrm{NA} \\ & & \\ \text { Hospital death } & 1,757 & 48.6 \\ \text { No } & 1,856 & 51.4 \\ \text { Yes } & \end{array}$

$\overline{\mathrm{Cl}}$, confidence interval; NA, not applicable; IQR, interquartile range; $y$, years

aJohns Hopkins ACG System's Resource Utilization Band is a Web site tracks an individual's health care utilization in the 2 years before their diagnosis. the 2 years before diagnosis, and an in-hospital death were associated with decreased home care costs. Among the predictor variables, in-hospital death had the largest effect on 30-day home care cost (Table 4).

For the subanalysis, 1,906 patients were alive for at least 180 days after their diagnosis (Figure 1). Their average 30-day cost over the 180 days was Can $\$ 820$. Home care costs and visits increased as patients neared death. The 30-day costs for home care at 1 month prior to a patient's death were almost 3 times higher than were the 30-day home care costs at 6 months prior to a patient's death. The number of visits more than doubled in the last month before death, compared with those in the 30-day period 6 months before a patient died (Figure 2 ). Over the 180-day period, the most common types of home care services were nursing (63.5\%) and personal support services (30.5\%); these remained constant in each 30-day period leading up to death.

\section{Discussion}

The evaluation is based on a large and representative sample of the Ontario population with stage IV colorectal cancer during the years analyzed. Close to $80 \%$ of the study population received publicly funded community home care services during the terminal phase of their illness. Over a 1-month period, metastatic colorectal cancer patients in terminal care received, on average, 8 home care visits, amounting to an average of 48 home care visits over the 6-month terminal phase. The average cost was about Can $\$ 800$ per month, or Can $\$ 4,800$ during the 6 months leading to death among those who survived at least 6 months. The cost in the terminal phase was made up of additional home nursing care and personal support services, likely for palliative management, treatment of metastatic disease, and/or end-of-life care. More home care visits and higher costs occurred as patients neared death, and these are also thought to be attributed to end-of-life care.

About $60 \%$ of the cohort had at least 1 palliative home care service during the terminal phase of care. Although this rate seems to be low, it should be noted that more than half of the cohort died in a hospital, thereby reducing their opportunity to receive home care. Undercoding of palliative services is also a potential explanation for the low rate of palliation observed in this study.

In our study, home care costs decreased if 
individuals had higher levels of previous health care utilization and if they died in an acute care hospital. Those who died outside of a hospital had incrementally higher home care costs (Can\$309), although we are unable to determine whether these out-of-hospital deaths occurred in a personal residence, a hospice, or a long-term care facility, which suggests that the differential could be even greater if a clear comparison between home and in-hospital death could be made.

Our results can be compared with those of other phasebased approaches to home care costing. Patients with stage IV colorectal cancer used more home care visits in the terminal phase than did breast cancer patients at the same stage. Results may differ because of sex and differential resource utilization for disease sites. ${ }^{7}$

Studies have shown that care in the community is less expensive than is institutional or residential care. ${ }^{17-21}$ Some of the home care costing work has been specific to palliative and end-of-life care. ${ }^{22-24}$ For example, researchers examined the cost of end-of-life care in Ontario (from 2002 through 2003) for a number of cancer sites. ${ }^{8}$ This study also used a 6-month time period prior to death in the analysis. Results showed that the average home care costs for individuals at the end of life were Can\$15,886 for all cancer sites and Can $\$ 15,269$ for colorectal cancer, costs that are much higher than what we calculated in our study. The reasons for the cost differences include the fact that patients were not stratified by stage of disease, and the investigators did not examine actual utilization but instead applied the maximum number of home care visits allowed by the system. It should be noted that the maximum number of allowable visits in that study greatly exceeded the average number of actual visits found in our cohort, and was based on only 1 region within the province. In another study, researchers examined administrative data from a Belgian health care organization, and reported that cancer patients had home care costs that were similar to ours over a 6-month time horizon, despite differences in the health care systems that were in place in the respective countries. ${ }^{4}$ In the United States, researchers examined end-of-life medical expenditures in a Medicare population who had been diagnosed with colorectal cancer..$^{9}$ Of these, $47 \%$ of the cohort who were older than 68 years at death received home care services, compared with almost $80 \%$ that we found in this study. Reasons for the differences include access to a different health system model, and the fact that our analysis included persons of all ages.

Unlike the United States, Canada does not have a formalized hospice system. ${ }^{5}$ It is estimated that $16 \%-30 \%$ of Canadians who die have access to or receive palliative and end-of-life care services from hospice. ${ }^{26} \mathrm{We}$ recognize that this represents a significant gap in the health care system, and that home care with a palliative designation may be a surrogate for hospice.
$\mathrm{N}=36,195$

Incident cases of colorectal cancer (2005-2009)

$n=25,224$

Cases with disease staging information

$\mathrm{n}=5,283$

Cases with stage IV colorectal cancer

$\mathrm{n}=3,613$

Cases with at least 180 days followup after diagnosis and before

their death

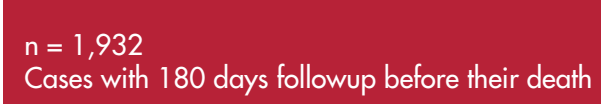

Cases with 180 days followup before their death

FIGURE 1 Breakdown of cohort selection

There are limitations associated with the use of administrative data. These administrative data do not reveal the purpose of the service, access to home care services, the efficiency of delivery of home care services, the effectiveness of patient care, the quality of the care, or even the appropriateness of home care. An examination of treatment-management guidelines for home care service utilization would be required to determine the appropriateness of the care.

In this study, the terminal phase is empirically defined.

TABLE 2 Type of home care services during terminal care phase among stage IV colorectal cancer patients who died during follow-up ${ }^{a}$

Type of home care service

No. of services Percentage

$\begin{array}{lll}\text { Visiting nurses } & 92,090 & 63.8 \\ \text { Homemaking/personal support providers } & 43,659 & 30.3\end{array}$

\begin{tabular}{lrl} 
Occupational therapists & 2,643 & 1.8 \\
Physiotherapists & 1,542 & 1.1 \\
\hline Patient management providers & 1,327 & 0.9 \\
Respite workers & 995 & 0.7 \\
Nutritionists/dieteticians & 793 & 0.5 \\
Social workers & 732 & 0.5 \\
Other & 354 & 0.2 \\
Speech language therapists & 51 & 0.0 \\
Psychologists & 22 & 0.0 \\
Placement service providers & 14 & 0.0 \\
Enterostomal therapists & 12 & 0.0
\end{tabular}

${ }^{a} N_{\text {total }}=144,234$ home care services; 2,866 patients received home care. 


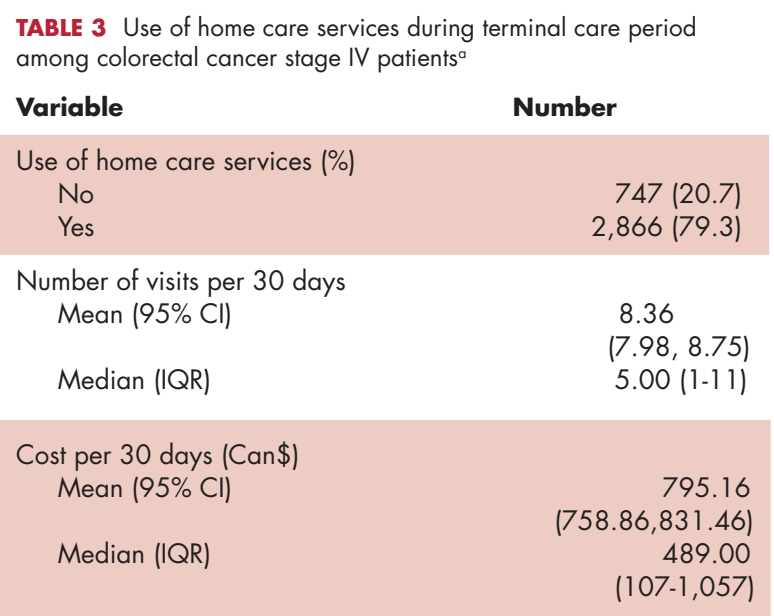

Can\$, Canadian dollar; $\mathrm{Cl}$, confidence ratio; IQR, interquartile range; $N$, total number

${ }^{\circ} \mathrm{N}=3,613$

The 6-month time horizon used in this analysis has been used in other studies examining resource utilization and costs associated with end of life care. ${ }^{4,6-8}$ Although other such studies have used 1 week, ${ }^{27} 1$ year ${ }^{5,9,28}$ or even 2 years $^{3}$ to define the terminal phase of care, we chose a 6-month time horizon because of the advanced stage of colorectal cancer at diagnosis.

The results of this analysis are representative of the colorectal cancer cohort that was selected from this provincial dataset. Population-based studies for other disease-site cohorts are required to examine similarities and differences in utilization and associated costs. ${ }^{18,22,24,29-34}$ Here, the data source was administrative data from Ontario and does not include privately funded home care services or services provided by family and friends. Data collection of primary care and home care records or access to private insurers' databases would be necessary to provide service level details. ${ }^{24}$

The palliative care flag is initiated by a palliative care team. If the patient is not registered with a palliative care team, it is possible that the service won't be flagged as palliative care at the end of life. This could explain the low rate found in this terminal population. Unfortunately, this is a limitation of the database.

Intercountry comparisons that use race as a covariate are not possible, as patient-level race and ethnicity data for the population are not collected in any of the usual sources of health system administrative data. Access to health care and, in this context, home care - and the ability to pay are not issues in Ontario because home care is an insured service under the universal health care system.

Finally, our results are presented as overall costs not attributable to net costs. The attributable cost of home care

TABLE 4 Regression coefficients estimate 30-day home care costs for stage IV colorectal cancer patients during terminal phase ${ }^{a, b}$

\begin{tabular}{|c|c|c|c|c|}
\hline Variable & $\begin{array}{l}\text { Parameter } \\
\text { estimate }\end{array}$ & $\begin{array}{l}\text { Standard } \\
\text { error }\end{array}$ & t value & $\begin{array}{c}\text { Replace with } \\
\text { P value }\end{array}$ \\
\hline $\begin{array}{l}\text { Intercept } \\
\text { Male }\end{array}$ & $\begin{array}{r}1,389.83 \\
-156.23\end{array}$ & $\begin{array}{l}92.66 \\
43.84\end{array}$ & $\begin{array}{l}15 \\
-3.56\end{array}$ & $\begin{array}{r}<.0001 \\
.0004\end{array}$ \\
\hline $\begin{array}{l}\text { Age group, }{ }^{c} y \\
\quad<45 \\
45-54 \\
65-74 \\
75-84 \\
\geq 85\end{array}$ & $\begin{array}{r}-52.91 \\
-28.45 \\
-69.91 \\
32.63 \\
103.32\end{array}$ & $\begin{array}{r}123.26 \\
76.94 \\
62.60 \\
63.47 \\
89.38\end{array}$ & $\begin{array}{r}-0.43 \\
-0.37 \\
-1.12 \\
0.51 \\
1.16\end{array}$ & $\begin{array}{l}.6678 \\
.7116 \\
.2642 \\
.6072 \\
.2478\end{array}$ \\
\hline $\begin{array}{l}\text { Income quintiled } \\
\text { Urban residents } \\
\text { Lowest } \\
\text { Second lowest } \\
\text { Middle } \\
\text { Second highest } \\
\text { Rural residents }\end{array}$ & $\begin{array}{r}-58.61 \\
-88.14 \\
67.47 \\
75.84 \\
-88.08\end{array}$ & $\begin{array}{l}75.18 \\
75.89 \\
73.11 \\
75.97 \\
75.24\end{array}$ & $\begin{array}{r}-0.78 \\
-1.16 \\
0.92 \\
1.00 \\
-1.17\end{array}$ & $\begin{array}{l}.4357 \\
.2456 \\
.3562 \\
.3183 \\
.2419\end{array}$ \\
\hline $\begin{array}{l}\text { Resource Utilization Ban } \\
\text { Healthy user } \\
\text { Low } \\
\text { Moderate } \\
\text { High } \\
\text { None }\end{array}$ & $\begin{array}{r}173.17 \\
-109.12 \\
-184.06 \\
-163.54 \\
-22.60\end{array}$ & $\begin{array}{r}237.29 \\
113.82 \\
61.32 \\
66.96 \\
181.93\end{array}$ & $\begin{array}{r}0.73 \\
-0.96 \\
-3.00 \\
-2.44 \\
-0.12\end{array}$ & $\begin{array}{l}.4656 \\
.3378 \\
.0027 \\
.0146 \\
.9011\end{array}$ \\
\hline Hospital death & -308.98 & 43.61 & -7.08 & $<.0001$ \\
\hline
\end{tabular}

${ }^{a} \mathrm{~N}=3,613$. ${ }^{b}$ Analysis among stage IV colorectal cancer patients with at least 1 home care visit during terminal period. ${ }^{\mathrm{c} R e f e r e n c e,} 55-64 \mathrm{y}$. ${ }^{\mathrm{d}} \mathrm{Reference,}$ 5 (Urban highest). eReference, 5 (Highest). 


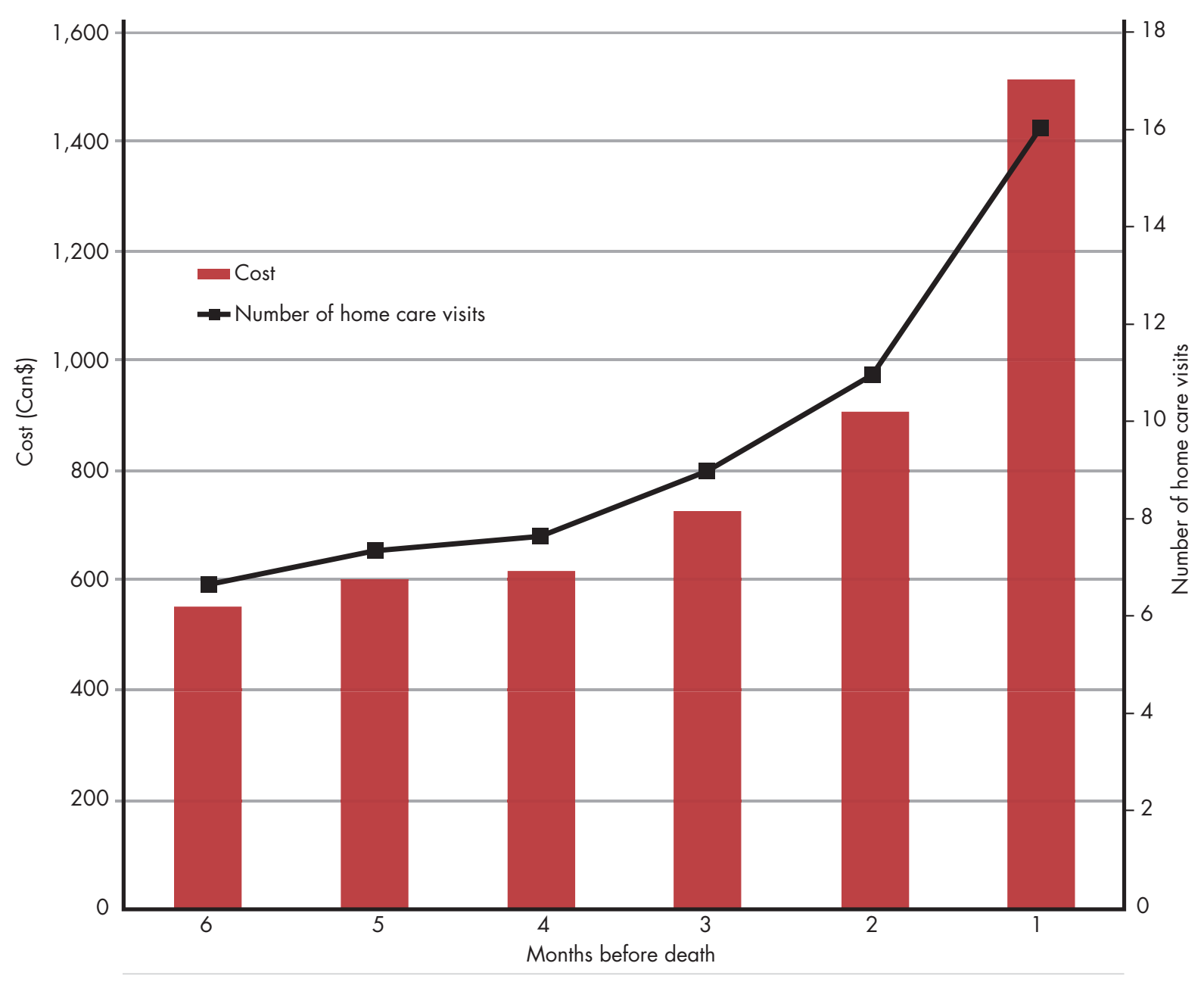

FIGURE 2 Cost and utilization of home care resources

for a cohort with advanced colorectal cancer, compared with those for a matched control group without cancer, was not evaluated. We decided to provide overall rather than incremental costs because of the difficulty of matching an advanced-stage colorectal cancer group to an appropriate control group. A recent report of community dwelling $\mathrm{Ca}^{-}$ nadian seniors showed that $25 \%$ of the population received some sort of home care (formal and/or informal), and that the amount of home care services provided increased with age and disability. ${ }^{2}$ In that study, only $3 \%$ of formal home care was for medical services. The actual type and number of services provided over a specific time horizon were not reported in this community dwelling population, which was assumed to be relatively healthy.

\section{Conclusions}

To date, the type and cost of home care services that are specific to the management of a single cancer type by the extent of disease present at diagnosis have not been exam- ined in a large population cohort. We found that individuals with advanced colorectal cancer at diagnosis cost the publicly funded home care system about Can $\$ 5,000$ in the terminal phase of their illness, which would amount to about Can $\$ 28$ per day for home care. If we were to apply this level of home care to all advanced-stage colorectal cancer patients $(\mathrm{N}=3,613$ from 2006 through 2009) in their last 6 months of life, the budget impact would be approximately Can $\$ 3.6$ million per year. Better understanding of the home care experience of individuals with advanced colorectal cancer may help inform future resource allocation decisions. Further work will focus on the cost implications of hospitalization for advanced colon cancer patients at the end of life.

\section{Acknowledgements}

The investigators thank Nelson Chong, Health Data Specialist, ICES, and Cancer Care Ontario's programmers for their help in untangling and linking the dataset. We are grateful to the grant coordinators (Thi Ho, Katrina Chan) for their administrative insight. We are also thankful for 
the costing expertise provided by Dr Walter Wodchis. We thank Marta Yurcan and Gemma Lee at Cancer Care Ontario for their assistance with the cancer-staging information. Finally, we are grateful to Grace Bannon and Soo Jin Seung for formatting assistance. The investigators note that the opinions, results, and conclusions reported in this paper are those of the authors. No endorsement by ICES, Cancer Care Ontario, or the Government of Ontario is intended or should be inferred.

\section{References}

1. Cancer Care Ontario. Cancer Fact: New cases of colorectal cancer increasing in Ontario. Cancer Care Ontario/Action Cancer Ontario. https://www.cancercare.on.ca/cancerfacts. Published March 2009. Accessed January 9, 2013.

2. Hoover M, Rotermann M. Seniors' use of and unmet needs for home care, 2009. Health Reports. 2012;23(4). Statistics Canada, catalogue No. 82-003-XWE. http://www.statcan.gc.ca/pub/82003-x/2012004/article/11760-eng.pdf.] Accessed January 9, 2013.

3. Fassbender K, Fainsinger RL, Carson M, Finegan BA.. Cost trajectories at the end of life: the Canadian experience.J Pain Symptom Manage. 2009;38:75-80.

4. Gielen B, Remacle A, Mertens R. Patterns of health care use and expenditure during the last 6 months of life in Belgium: differences between age categories in cancer and non-cancer patients. Health Policy. 2010;97:53-61.

5. Kardamanidis K, Lim K, Da Cunha C, Taylor LK, Jorm LR. Hospital costs of older people in New South Wales in the last year of life. Med J Aust. 2007;187:383-386.

6. Kelley AS, Ettner SL, Morrison RS, Du Q, Wenger NS, Sarkisian CA. Determinants of medical expenditures in the last 6 months of life. Ann Intern Med. 2011;154:235-242.

7. Mittmann N, Isogai PK, Saskin R, et al. Population-based home care services in breast cancer: utilization and costs. Curr Oncol. 2012;19:e383-e391.

8. Walker H, Anderson M, Farahati F, et al. Resource use and costs of end-of-life/palliative care: Ontario adult cancer patients dying during 2002 and 2003. J Palliat Care. 2011;27:79-88.

9. Shugarman LR, Bird CE, Schuster CR, Lynn J. Age and gender differences in Medicare expenditures at the end of life for colorectal cancer decedents. J Womens Health (Larchmt). 2007;16:214-227.

10. Cancer Care Ontario. https://www.cancercare.on.ca/ocs/csurv/stats/ ocr/. Accessed February 13, 2013.

11. International Classification of Disease, ninth revision. http://www. who.int/classifications/icd/en/, Accessed February 13, 2014.

12. American Joint Committee on Cancer. https://cancerstaging.org/ Pages/default.aspx. Accessed February 13, 2014.

13. Bank of Canada. Daily currency converter. http://www.bankofcanada.ca/rates/exchange/daily-converter/. Accessed December 20, 2012.

14. Wodchis, WP, Bushmeneva, K, Nikitovic, M., McKillop, I. Guidelines on person-level costing using administrative databases in Ontario. Working Paper Series. Vol 1. Toronto: Health System Performance Research Network; 2013. http://www.hsprn.ca/activities/ papers/hsprn_case_costing_vol1_2013.pdf. Accessed February 13, 2014.

15. Wilkins R, Berthelot JM, Ng E. Trends in mortality by neighbourhood income in urban Canada from 1971 to 1996. Health Reports. 2002;13(suppl):1-27.

16. The John Hopkins ACG System. http://acg.jhsph.org/?option=com content\&view=article\&id=131\&Itemid=169. Accessed February 13, 2014.
17. Armstrong CD, Hogg WE, Lemelin J, et al. Home-based intermediate care program vs hospitalization: cost comparison study. Can Fam Physician. 2008;54:66-73.

18. Evans WK, Will BP, Berthelot JM, Logan DM, Mirsky DJ, Kelly $\mathrm{N}$. Breast cancer: better care for less cost. Is it possible? Int J Technol Assess Health Care. 2000;16:1168-1178.

19. Hollander MJ, Chappell NL. A comparative analysis of costs to government for home care and long-term residential care services, standardized for client care needs. Can J Aging. 2007;26(suppl 1):149-161.

20. Ontario Ministry of Finance. Ministry of Health and Long-Term Care: The estimates, 2011-12, Summary. http://www.fin.gov.on.ca/ en/budget/estimates/2011-12/volume1/MOHLTC.html. Updated April 19, 2011. Accessed June 1, 2012.

21. Subirana Serrate R, Ferrer-Roca O, González-Dávila E. A costminimization analysis of oncology home care versus hospital care. J Telemed Telecare. 2001;7:226-232.

22. Dumont S, Jacobs P, Fassbender K, Anderson D, Turcotte V, Harel F. Costs associated with resource utilization during the palliative phase of care: a Canadian perspective. Palliat Med. 2009;23:708717.

23. Fassbender K, Fainsinger R, Brenneis C, Brown P, Braun T, Jacobs P. Utilization and costs of the introduction of system-wide palliative care in Alberta, 1993-2000. Palliat Med. 2005;19:513-520.

24. Johnson AP, Abernathy T, Howell D, Brazil K, Scott S. Resource utilisation and costs of palliative cancer care in an interdisciplinary health care model. Palliat Med. 2009;23:448-459.

25. Canadian Cancer Society. Canadian cancer statistics 2010: Special topic: end-of-life care. Toronto: Canadian Cancer Society; 2010.

26. Canadian Institute of Health Information. Health care use at the end of life in Western Canada. Ottawa: Canadian Institute for Health Information; 2007.

27. Zhang B, Wright AA, Huskamp HA, et al. Health care costs in the last week of life: associations with end-of-life conversations. Arch Intern Med. 2009;169:480-488.

28. Shmueli A, Messika D, Zmora I, Oberman B. Health care costs during the last 12 months of life in Israel: estimation and implications for risk-adjustment. Int J Health Care Finance Econ. 2010;10:257-273

29. Anderson MA, Pena RA, Helms LB. Homecare utilization by congestive heart failure patients: a pilot study. Public Health Nurs. 1998; 15:146-162.

30. Hawranik PG, Strain LA. Cognitive impairment, disruptive behaviors, and home care utilization. West J Nurs Res. 2001;23:148-62.

31. King MT, Hall J, Caleo S, Gurney HP, Harnett PR. Home or hospital? An evaluation of the costs, preferences, and outcomes of domiciliary chemotherapy. Int J Health Serv. 2000;30:557-579.

32. Kouli E, Kaitelidou D, Kalokerinou-Anagnostopoulou A, Siskou O. The cost of home care for patients with malignant neoplasms. Home Healthc Nurse. 2008;26:594-599.

33. Lee T, Kovner CT, Mezey MD, Ko IS. Factors influencing longterm home care utilization by the older population: implications for targeting. Public Health Nurs. 2001;18:443-449.

34. Oliver MJ, Quinn RR, Richardson EP, Kiss AJ, Lamping DL, Manns BJ. Home care assistance and the utilization of peritoneal dialysis. Kidney Int. 2007;71:673-678. 